Pak. j. sci. ind. res. Ser. A: phys. sci. 2018 61A(1) 51-55

\title{
Evaluation of Metals and Organic Contents in Locally Available Eye Shadow Products in Lahore, Pakistan
}

\author{
Amina Abrar*, Sofia Nosheen, Faiza Perveen and Moneeza Abbas \\ Department of Environmental Science, Lahore College for Women University, Lahore, Pakistan
}

(received February 7, 2017; revised June 2, 2017; accepted August 16, 2017)

\begin{abstract}
This study was conducted to evaluate the concentration of some heavy metals (lead, cadmium, chromium and zinc) and synthetic organic contents in non branded eye shadows locally available in Lahore, Pakistan. Twenty five samples of five eye shadow colours (red, golden, orange, white and pink) were purchased from local market in Lahore. Samples were pre-treated and atomic absorption spectrometer was used to determine the concentration of lead $(\mathrm{Pb})$, cadmium $(\mathrm{Cd})$, chromium $(\mathrm{Cr})$ and zinc $(\mathrm{Zn})$. Total organic content in these samples was determined by wet oxidation technique. Maximum concentration of $\mathrm{Pb}$ in eye shadow samples was detected to be $15.33 \mu \mathrm{g} / \mathrm{g}$. Concentration of $\mathrm{Pb}$ in $80 \%$ of samples was found to be higher as compared to the permissible limit $(10 \mu \mathrm{g} / \mathrm{g})$ of $\mathrm{Pb}$ in cosmetics provided by Health Canada. 26\% samples showed Cd concentration higher than permissible limit ( $3 \mu \mathrm{g} / \mathrm{g})$. Although there are no available internationally acceptable maximum limits for $\mathrm{Cr}$ and $\mathrm{Zn}$, but these metals were found to be present in detectable limits ranging from $5.5-8.23 \mu \mathrm{g} / \mathrm{g}$ and $7.9-11.84 \mu \mathrm{g} / \mathrm{g}$, respectively. Total organic content (TOC) in the samples was found to be ranging from $2.15-2.92 \mathrm{mg} / \mathrm{g}$.
\end{abstract}

Keywords: eye shadows, heavy metals, permissible limit, organic contents

\section{Introduction}

Cosmetics are applied directly to human skin, hair and nail therefore, these should be safe for health. Heavy metals in cosmetics are considered toxic to human body (Bocca et al., 2014). These are considered a part of routine body care in all strata of society. An average adult uses nine cosmetics daily and more than $25 \%$ women use 15 or more (Chauhan et al., 2010). Eye shadows are a typical example of pigmented make-up products used by women all over the world. Among the hazardous substances contained in cosmetics, heavy metals are widely diffused in coloured makeup products.

As the issues of heavy metals have been addressed, attention is turned to the presence of these substances as impurities. The deliberate use of metals as active ingredients in cosmetic products is prohibited by legislation in most countries, but metal impurities do exist in such products due to their persistence and ubiquitous nature. Metals such as $\mathrm{Cd}, \mathrm{Pb}, \mathrm{Ni}, \mathrm{Cr}$ and $\mathrm{Co}$ are retained as impurities in the pigments of eye shadows or released by the metallic devices used during the manufacturing of these products. The continuous use of these cosmetic products could lead to the absorption of metals through skin. $\mathrm{Cd}$ and $\mathrm{Zn}$ exist in

*Author for correspondence;

E-mail: amina.abrar@outlook.com pigments and all other raw materials in all industries including the cosmetics industry (Nnorom, 2011).

There is a connection between use of makeup at young age and skin allergies by heavy metal contaminants in makeup. It has been found that young girls do react to these metals especially if they are prone to skin allergies or have damaged skin, such as from scrapes or cuts (Corazza et al., 2009). In an American survey consisting of 30,000 consumers, 700 reactions occurred during one year period and was estimated that $1-3 \%$ of the populations were allergic to a cosmetic or cosmetic ingredients (Mehta and Reddy, 2003). Use of cosmetic products is increasing rapidly all over the world and various toxic chemicals including heavy metals are used in the production of cosmetics which can cause health risks to consumer especially low cost products. Heavy metal toxicity takes place in the form of various diseases when inhaled or absorbed through skin (Saeed et al., 2011).

Skin absorption of heavy metals salts varies greatly with different physical parameters (Ullah et al., 2017). Heavy metal ions when come in contact with human body, they get absorbed and form complexes with carboxylic acid $(-\mathrm{COOH})$, amine $\left(-\mathrm{NH}_{2}\right)$, and thiol $(-\mathrm{SH})$ of proteins resulting in dis-functioning or death of the cells and consequently lead to a variety of diseases (Flora and Pachauri, 2010). Some cosmetics are benign, 
others can cause harmful effects such as cancer, allergies, mutations, respiratory diseases as well as reproductive problems (CDC, 2003).

Heavy metal exposure leads to metal toxicity. Characteristic features of lead toxicity include anemia, neuropathy, nephropathy and coma. Exposure of human body to low-levels of lead has also been linked with abnormalities in human behaviour, learning impairment, and decreased hearing in humans and in experimental animals (Chauhan et al., 2010). Zinc and lead develop same signs of illness and can easily be diagnosed as lead poisoning (Theresa et al., 2011). An increase level of cadmium is a cause of inhibition of DNA mismatches. Inhaling large amount of cadmium can cause stomach, kidney and liver problems, nose redness, irritation, nosebleed, runny nose and even death. When skin comes in contact with chromium compounds, it results in skin ulcers (Gondal et al., 2010).

Hexavalent chromium $\left(\mathrm{Cr}^{+6}\right)$ cause allergies of the skin. $\mathrm{Cr}^{+6}$ compounds are classified as carcinogens by the International Agency for Research on Cancer (IARC). Toxic effects of the $\mathrm{Cr}^{+6}$ on the skin may result in ulcerations, dermatitis, and skin allergies. Inhalation of $\mathrm{Cr}^{+6}$ compounds can result in ulceration and pores in the mucous membranes of the nasal septum, discomfort of the pharynx and larynx and asthmatic bronchitis. Respiratory symptoms may include coughing, shortness of breath, and nasal itch (Sahu et al., 2014). It can cause increased blood leukocytes, wounds of eye and skin ulcers by inhalation, ingestion, and by skin and eye contact (CDCP, 2014).

Pakistan has no technologically developed cosmetic industry. There are certain rules and safety limits for regulating the use of chemicals (both organic as well as inorganic) but these rules are not followed in small scale, local and cheap industries, so there is a need to focus on this area of investigation. A major proportion of Pakistani population has low income status and low literacy rate so they use mostly locally available cosmetics. The present study was therefore, taken to give attention to a very critical issue.

\section{Materials and Methods}

The study was carried out to detect heavy metals contents (lead, cadmium, chromium and zinc) and total organic content in eye shadows purchased from local market in Lahore. Different eye shadows (red, golden, orange, white and pink), the most commonly used colours were selected and total 25 samples were analysed.

Determination of heavy metals. Glasswares were washed thoroughly with detergent and dilute nitric acid and rinsed with distilled water before use. Each sample kit was dealt separately to avoid any cross contamination. All pellets of each colour in eye shadow kit were taken out and weighed accurately for further processing. One gram of each sample was placed into a $100 \mathrm{~mL}$ glass beaker. Weighed sample was digested with $5 \mathrm{~mL}$ of concentrated nitric acid on a hot plate at $80^{\circ} \mathrm{C}$ until the sample was dried. Once the sample was dried, the process was repeated again by adding $5 \mathrm{~mL}$ of concentrated nitric acid and dried on a hot plate at $80^{\circ} \mathrm{C}$. Then $1 \mathrm{~mL}$ of concentrated hydrogen peroxide $\left(\mathrm{H}_{2} \mathrm{O}_{2}\right)$ was added in order to oxidise the organic matter of residues completely. The residual material was diluted by using de-ionized water to the final volume of $50 \mathrm{~mL}$. The solution was then filtered by Whatman filter paper. Same procedure was repeated for all samples. Samples prepared for determination of the metal ions in the solution were kept in test tubes, covered by aluminum foil and stored in cool incubator until analysed (Nourmoradi et al., 2013). Atomic absorption spectrophotometer (AAS Thermo Scientific M series GF95Z Zeeman, Furnace) was used for metal analysis. A standard stock solution of $1000 \mathrm{mg} / \mathrm{L}$ was diluted into series of standard solutions (2, 4 and $6 \mathrm{ppm})$ up to the level of distilled water. The standard stock solution was further diluted into series of standard solution (1, 2 and 3 ppm) up to the mark with distilled water. Concentrations of lead, cadmium, chromium and zinc was determined in eye shadow samples by AAS. Mean concentration of each heavy metal was calculated and the results were compared with the permissible limits of these metals in cosmetics provided by Health Canada.

Determination of total organic content. Organic content was determined in terms of total organic carbon in eye shadows. For determination of organic content the wet oxidation method was employed using exothermic heating. It involved oxidation of carbon content with potassium dichromate $(1 \mathrm{~N})$ as oxidizing agent along with concentrated sulphuric acid. In the second step excess dichromate (leftover) was titrated with 0.5 $\mathrm{N}$ ferrous ammonium sulphate solution till end point was achieved. Diphenylamine was added as indicator. The solution was back titrated with $0.5 \mathrm{~N}$ ferrous solution (Avramidisa et al., 2015; Gaudette et al., 1974). 


\section{Results and Discussion}

The analysis of eye shadow samples of different brands showed detectable amount of heavy metals impurities but with varying concentrations. Health Canada has recommended that the maximum $\mathrm{Pb}$ concentration in cosmetics to be lesser than $10 \mu \mathrm{g} / \mathrm{g}$ while Cd permissible limit in cosmetics is $3 \mu \mathrm{g} / \mathrm{g}$ (Hazard, 2011). Results of present study showed mean concentration of $\mathrm{Pb}$ ranging from 7.56-15.33 $\mu \mathrm{g} / \mathrm{g}$ in selected eye shadow colours (Fig. 1). $80 \%$ of samples were having $\mathrm{Pb}$ content higher than the permissible limit of $10 \mu \mathrm{g} / \mathrm{g}$. Lead is considered a very dangerous heavy metal in cosmetics, but is largely used in the make-up items. Lead impairs the renal, homopoietic and nervous system. Reports of various surveys suggest that $\mathrm{Pb}$ is casually related to deficiency in cognitive functioning. Mean concentration of $\mathrm{Cd}$ in different colours was found to be ranging from 0.41 $2.23 \mu \mathrm{g} / \mathrm{g}$ (Fig. 1). Although mean concentration of $\mathrm{Cd}$ in different colours was found to be within the permissible limit of $3 \mu \mathrm{g} / \mathrm{g}$ but $26 \%$ of individual samples had higher Cd content as compared to the permissible limit established by Health Canada.

Mousavi et al. (2013) also reported high content of $\mathrm{Pb}$ and $\mathrm{Cd}$ in eye shadows purchased from local market in Tehran, Iran. They also reported that the type of pigment used in eye shadows contributes to its heavy metal content, brown and golden colours in all brands have the highest concentrations of lead, while blue and green colours have the lowest lead content and the golden and blue colour have the highest and lowest concentration of cadmium, respectively. The present study

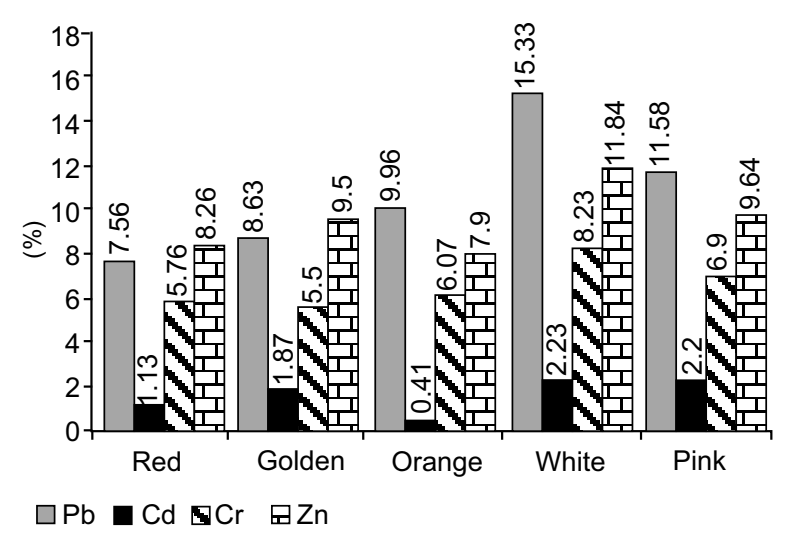

Fig. 1. Mean concentrations in $\mu \mathrm{g} / \mathrm{g}$ of $\mathrm{Pb}, \mathrm{Cd}, \mathrm{Cr}$ and $\mathrm{Zn}$ in (red, golden, orange, white and pink) eye shadows randomly purchased from local market in Lahore, Pakistan. showed higher concentration of $\mathrm{Pb}$ in pink and white colours than in other colours while pink and white colours were also having higher concentrations of $\mathrm{Cd}$ as well. Another research study conducted by Nourmoradi et al. (2013) to assess lead and cadmium levels in frequently used cosmetic products in Iran, showed higher concentration of $\mathrm{Pb}$ and $\mathrm{Cd}$ in eye shadows ranging from $0.85-6.90 \mu \mathrm{g} / \mathrm{g}$ and $1.54-55.59 \mu \mathrm{g} / \mathrm{g}$, respectively.

The present study showed mean concentration of $\mathrm{Zn}$ in different eye shadow colours to be ranging from 7.9$11.84 \mu \mathrm{g} / \mathrm{g}$ and mean concentration of $\mathrm{Cr}$ to be ranging from 5.5-8.23 $\mu \mathrm{g} / \mathrm{g}$ (Fig. 1). There are no permissible limits of $\mathrm{Cr}$ and $\mathrm{Zn}$ found in cosmetics but the present study showed detectably high amount of these metals in different eye shadow colours. A study on determination of chromium in cosmetics conducted by Zhou et al. (2011) showed high concentration of $\mathrm{Cr}$ in majority of the cosmetics available in the market of China. High concentration of $\mathrm{Zn}$ and $\mathrm{Cr}$ in eye shadows can lead to systemic contact dermatitis (SCD). Contact dermatitis is produced by external skin exposure to metals like chromium, zinc, cobalt and arsenic. A review study conducted by Yoshihisa and Shimizu (2012) reported that when exposed to skin, chromium salts can induce cutaneous irritation, which may progress to SCD in cases of chromium hypersensitivity. Zinc is an essential trace element involved in many physiological functions, including catalytic and structural roles in metalloenzymes, as well as regulatory roles in diverse cellular processes, such as synaptic signaling and gene expression. Compared to several other metal ions with similar chemical properties, zinc is relatively harmless. Only exposure to high doses has toxic effects, making acute zinc intoxication, a rare event. In addition to acute intoxication, long-term, high-dose zinc supplementation interferes with the uptake of copper. Hence, many of its toxic effects are in fact due to copper deficiency. Skin exposure to zinc can also lead to zinc allergies and SCD as reported in many studies (Plum et al., 2010).

High metal content in cosmetics applied on skin can be absorbed in blood and accumulate in various organs to produce toxic and allergic effects. Skin allergies and contact dermatitis are topical effects due to exposure to heavy metals in various cosmetics (Boroska and Brzoska, 2015).

Sainio et al. (2000) conducted a research study to detect the metal content in eye shadows. The results indicated 
that 66 out of $88(75 \%)$ of the colours contained more than $5 \mathrm{ppm}$ of at least one of the elements, and all 49 products contained more than one ppm of at least 1 of the elements. They also determined the systemic and topical effects of metals in eye shadows and found that eye shadows generally have no systemic toxicity but can pose a great risk of allergies. Another study conducted by Oh et al. (2016) investigated the contact allergens in eye shadow products. They found heavy metals to be one of the major contact allergens in eye shadows responsible for eyelid dermatitis. They found eye shadow products having significant amount of nickel, cobalt or chromium to elicit allergic reactions.

In current study organic content was also detected in samples. As products were not labeled as organic product so it was assumed that it should show no detectable contents of organic carbon. But a reasonably high level was determined in eye shadows ranging from 2.15-2.92 $\mathrm{mg} / \mathrm{g}$ (Fig. 2). Synthetic organic contents have the ability to affect the skin in a variety of unpleasant ways for a long time regular use like coal tar and di-ethanol amine. Presence of organic contents along with heavy metals potencies the alarming condition of these cheap local cosmetic products. Quality assurance with health significance should be practiced before market availability of the cosmetic products.

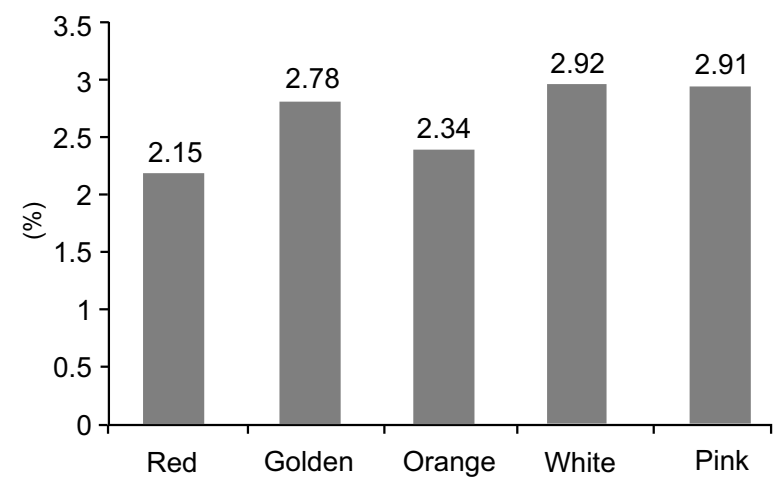

Fig. 2. Mean concentrations in $\mathrm{mg} / \mathrm{g}$ of organic content in (red, golden, orange, white and pink) eye shadows randomly purchased from local market in Lahore, Pakistan.

\section{Conclusion}

The present study showed that the quality of eye shadow purchased from local markets of Lahore was found unsatisfactory. $80 \%$ samples showed high $\mathrm{Pb}$ contents while 26\% samples showed Cd contents above the permissible limits. Detectable amounts of $\mathrm{Cr}$ and $\mathrm{Zn}$ impurities were also present in the eye shadows along with high organic content. Higher concentration of these metals and organic content in eye shadows can cause allergies, dermatitis, skin irritation or eczemas on eyelid skin. They can also accumulate in body and cause systematic effects. There is no proper safety standards in Pakistan related to heavy metal contamination in eye shadows or in other cosmetics products. Therefore, it is difficult to ascertain if the values of metals obtained in this study are very high or low. Further studies can be conducted on exposure assessment of these cosmetics.

\section{References}

Avramidis, P., Nikolaou, K., Bekiari, V. 2015. Total organic carbon and total nitrogen in sediments and soils: a comparison of the wet oxidation-titration method with the combustion-infrared method. Agriculture and Agricultural Science Procedia, 4: 425-430.

Bocca, B., Pino, A., Alimonti, A., Forte, G. 2014. Toxic metals contained in cosmetics: a status report. Regulatory Toxicology and Pharmacology, 68: 447-467.

Borowska, S., Brzóska, M.M. 2015. Metals in cosmetics: implications for human health. Journal of Applied Toxicology, 35: 551-572.

CDCP, 2014. NOISH Pocket Guide to Chemical Hazards: Chromic Acid and Chromates. Centers for Disease Control and Prevention. Online:

CDCP, 2003. Second National Report on Human Exposure to Environmental Chemicals. Centers for Disease Control and Prevention. Online: .

Chauhan, A.S., Bhadauria, R., Singh, A.K., Lodhi, S.S., Chaturvedi, D.K., Tomar, V.S. 2010. Determination of lead and cadmium in cosmetic products. Journal of Chemical and Pharmaceutical Research, 2: 9297.

Corazza, M., Baldo, F., Pagnoni, A., Miscioscia, R., Virgili, A. 2009. Measurement of nickel, cobalt and chromium in toy make-up by atomic absorption spectroscopy. Acta Dermato-Venereologica, 89: 130-133.

Flora, S.J., Pachauri, V. 2010. Chelation in metal intoxication. International Journal of Environmental Research and Public Health, 7: 2745-2788.

Gaudette, H.E., Flight, W.R., Toner, L., Folger, D.W. 
1974. An inexpensive titration method for the determination of organic carbon in recent sediments. Journal of Sedimentary Research, 44: 249-253.

Gondal, M.A., Seddigi, Z.S., Nasr, M.M., Gondal, B. 2010. Spectroscopic detection of health hazardous contaminants in lipstick using laser induced breakdown spectroscopy. Journal of Hazardous Materials, 175: 726-732.

Hazard, H.M. 2011. Report: The Heavy Metals Hazard: The Health Risks of Hidden Heavy Metals in Face Makeup. Environmental Defence, Toronto, Canada.

Mehta, S.S., Reddy, B.S.N. 2003. Cosmetic dermatitiscurrent perspectives. International Journal of Dermatology, 42: 533-542.

Mousavi, Z., Ziarati, P., Shariatdoost, A. 2013. Determination and safety assessment of lead and cadmium in eye shadows purchased in local market in Tehran. Journal of Environmental and Analytical Toxicology, 3: 2161-0525.

Nnorom, I.C. 2011. Trace metals in cosmetic facial talcum powders marketed in Nigeria. Toxicological \& Environmental Chemistry, 93: 1135-1148.

Nourmoradi, H., Foroghi, M., Farhadkhani, M., Vahid Dastjerdi, M. 2013. Assessment of lead and cadmium levels in frequently used cosmetic products in Iran. Journal of Environmental and Public Health, http://dx.doi.org/10.1155/2013/ 962727.

Oh, J.E., Lee, H.J., Choi, Y.W., Choi, H.Y., Byun, J.Y. 2016. Metal allergy in eyelid dermatitis and the evaluation of metal contents in eye shadows. Journal of the European Academy of Dermatology and Venereology, 30: 1518-1521.
Plum, L.M., Rink, L., Haase, H. 2010. The essential toxin: impact of zinc on human health. International Journal of Environmental Research and Public Health, 7: 1342-1365.

Saeed, M., Muhammad, N., Khan, H. 2011. Assessment of heavy metal content of branded Pakistani herbal products. Tropical Journal of Pharmaceutical Research, 10: 499-506.

Sahu, M.R., Saxena, M.P., Johnson, S., Mathur, H.B., Agarwal, H.C. 2014. Heavy Metals in Cosmetics. 28 pp., Pollution Monitoring Laboratory, Centre for Science and Environment, New Delhi, India.

Sainio, E.L., Jolanki, R., Hakala, E., Kanerva, L. 2000. Metals and arsenic in eye shadows. Contact Dermatitis, 42: 5-10.

Theresa, O.C., Onebunne, O.C., Dorcas, W.A., Ajani, O.I. 2011. Potentially toxic metals exposure from body creams sold in Lagos, Nigeria. Researcher, 3: 30-37.

Ullah, H., Noreen, S., Rehman, A., Waseem, A., Zubair, S., Adnan, M., Ahmad, I. 2017. Comparative study of heavy metals content in cosmetic products of different countries marketed in Khyber Pakhtunkhwa, Pakistan. Arabian Journal of Chemistry, 10: 10-18.

Yoshihisa, Y., Shimizu, T. 2012. Metal allergy and systemic contact dermatitis: an overview. Dermatology Research and Practice, doi:10.1155/2012/ 749561.

Zhou, L.Y., Huang, J., Ning, Z.Y., Cai, L., Li, C.X. 2011. Determination of Cr (VI) in cosmetics by FAAS after cloud point extraction. Guangzhou Chemical Industry, 4: 1-5. 